\title{
Evaluation and classification of pulmonary arterial hypertension
}

\author{
Sandeep Sahay \\ Division of Pulmonary and Critical Care Medicine, Weill Cornell Medical College, Institute of Academic Medicine, Houston Methodist Hospital, \\ Houston, TX, USA \\ Correspondence to: Sandeep Sahay, MD. Smith Tower, Houston Methodist Hospital, 6550 Fannin St, Ste 401, Houston, TX 77030 , USA. \\ Email: ssahay@houstonmethodist.org.
}

\begin{abstract}
In early 2019, the 6th World Symposium on Pulmonary Hypertension (WSPH) released an updated document highlighting the advances in the last five years. During the quinquennial event many experts worked together to suggest new changes in the disease diagnosis and management. Since inception of the WSPH in 1973, this is the first time when the hemodynamic definition of pulmonary hypertension (PH) has been updated. These proceedings have re-defined the different hemodynamic types of $\mathrm{PH}$ that occur with the left heart disease along with introduction to the genetic testing as part of pulmonary arterial hypertension $(\mathrm{PAH})$ evaluation. Objective of this review is to highlight the evaluation and diagnosis of $\mathrm{PAH}$ based on the proceedings of the 6th WSPH. Accurate early diagnosis and subsequent management of $\mathrm{PH}$ is necessary, as despite of treatment advances, survival remains suboptimal.
\end{abstract}

Keywords: Pulmonary hypertension (PH); 6th World Symposium on Pulmonary Hypertension (6th WSPH); pulmonary arterial hypertension (PAH); chronic thromboembolic pulmonary hypertension (CTEPH); pulmonary veno-occlusive disease (PVOD)

Submitted May 06, 2019. Accepted for publication May 21, 2019.

doi: $10.21037 /$ jtd.2019.08.54

View this article at: http://dx.doi.org/10.21037/jtd.2019.08.54

\section{Introduction}

Pulmonary hypertension $(\mathrm{PH})$ is a relentless, progressive disease which often leads to premature death. $6^{\text {th }}$ World symposium on pulmonary hypertension (WSPH) created 13 task forces with 124 experts from around the world to review and update the most recent scientific evidence on the evaluation, diagnosis and management of $\mathrm{PH}$ (1). With each update every five year, the society of the world experts work together to improve understanding of this disease, as management of this disease is still challenging and life expectancy is still suboptimal.

$\mathrm{PH}$ is classified into five groups. The group 1 pulmonary arterial hypertension (PAH), which comprises of diverse diseases that result in similar pathological changes within the pulmonary vasculature. This includes idiopathic, familial, drug and toxin induced PAH and associated forms of PAH like systemic sclerosis, portal hypertension, congenital heart disease and human immunodeficiency virus (HIV). The remaining 4 groups of $\mathrm{PH}$ are secondary to other conditions and are usually referred to as secondary PH (2). Treatment of these groups is focused towards correcting the underlying original condition. Group I $\mathrm{PAH}$ is the most important of all due to its aggressive nature, poor survival and limited treatment options. With efforts over the last three decades, group 1 PAH survival has improved but is still suboptimal and continues to be an unmet challenge. Registry to Evaluate Early And Long term PAH disease management study (REVEAL) showed five year survival of $57 \%$ from the time of diagnostic right heart catheterization (3).

The most controversial recommendations from these proceedings have been the proposal of a new hemodynamic definition of PH. This is the first time, since 1973 (the inception of WSPH), that the definition of $\mathrm{PH}$ has been changed (2). These changes are now a topic of active debate within the scientific community. This review will focus on the classification and evaluation of $\mathrm{PH}$ based on the $6^{\text {th }}$ WSPH proceedings. 
Table 1 Updated clinical classification of pulmonary hypertension (PH) (adapted from 6th WSPH document)

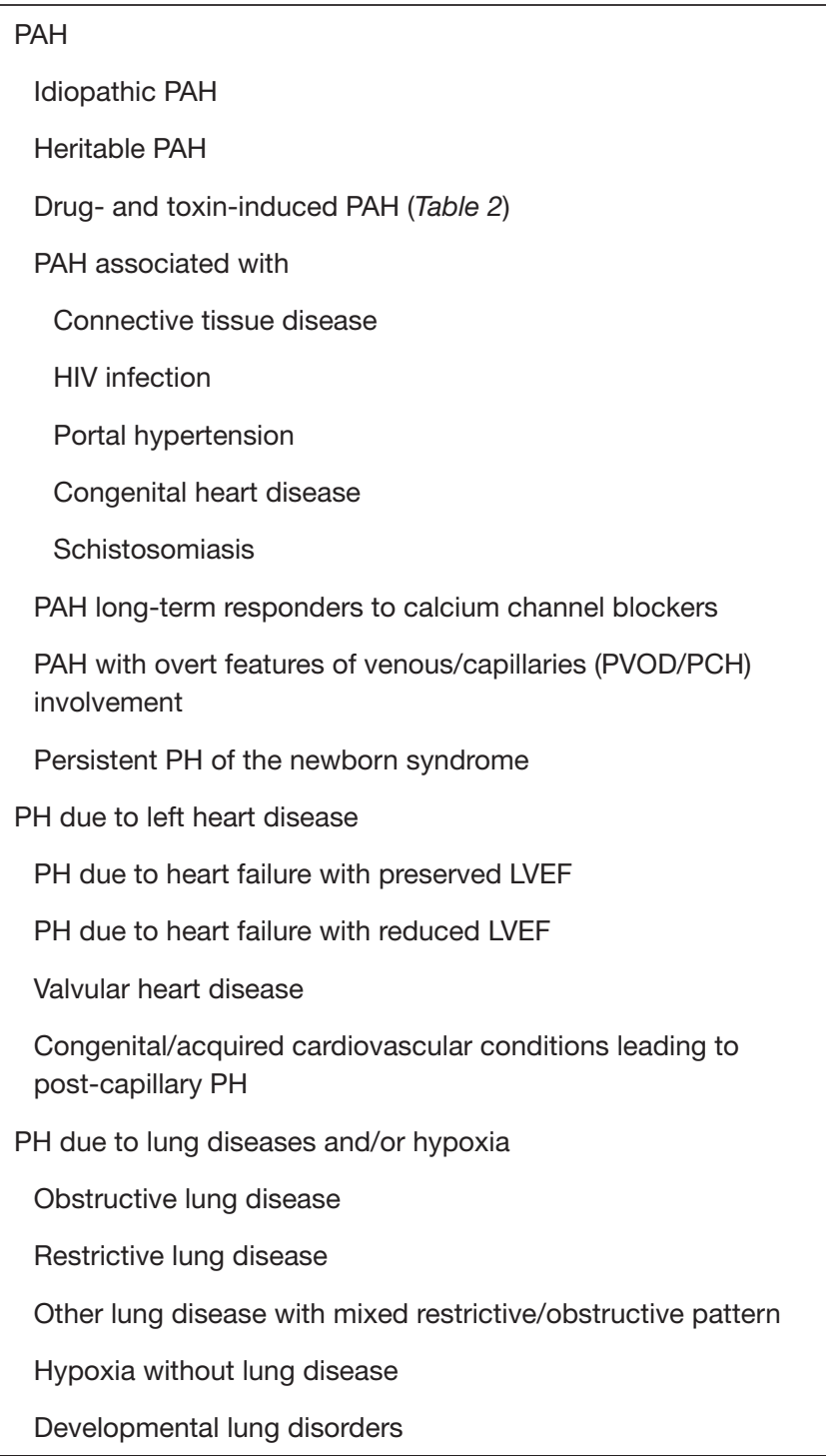

Table 1 (continued)

\section{Updated clinical classification of PH}

The current classification of $\mathrm{PH}$ categorizes clinical conditions associated with $\mathrm{PH}$ based on similar pathophysiology, etiologies, clinical presentation, hemodynamic characteristics and therapeutic management. The most updated clinical classification of $\mathrm{PH}$ in adults is presented in Table 1. $6^{\text {th }} \mathrm{WSPH}$ for the first time included $\mathrm{PAH}$ patients who are long term responders to calcium channel blockers (CCB) as a separate entity. Additionally
Table 1 (continued)

PH due to pulmonary artery obstructions
Chronic thromboembolic $\mathrm{PH}$
Other pulmonary artery obstructions
Sarcoma (high or intermediate grade) or angiosarcoma
Other malignant tumours
Renal carcinoma
Uterine carcinoma
Germ cell tumours of the testis
Other tumours
Non-malignant tumours: uterine leiomyoma
Arteritis without connective tissue disease
Congenital pulmonary artery stenoses
Parasites

$\mathrm{PH}$ with unclear and/or multifactorial mechanisms

Haematological disorders: chronic haemolytic anaemia myeloproliferative disorders

Systemic and metabolic disorders: pulmonary Langerhans cell histiocytosis, Gaucher disease, glycogen storage disease, neurofibromatosis, sarcoidosis

Others: chronic renal failure with or without hemodialysis, fibrosing mediastinitis

Complex congenital heart disease

Segmental pulmonary hypertension: isolated pulmonary artery of ductal origin, absent pulmonary artery, pulmonary atresia with ventricular septal defect and major aorto-pulmonary collateral arteries, hemitruncus, other

Single ventricle: unoperated, operated

Scimitar syndrome

PAH, pulmonary arterial hypertension; PVOD, pulmonary venoocclusive disease; $\mathrm{PCH}$, pulmonary capillary haemangiomatosis; LVEF, left ventricular ejection fraction.

pulmonary veno-occlusive disease (PVOD), pulmonary capillary hemangiomatosis $(\mathrm{PCH})$ and persistent $\mathrm{PH}$ of the newborn syndrome is also included in this group (2). The group $2 \mathrm{PH}$ is secondary to the left heart diseases like systolic or diastolic heart failure, left sided valvular diseases and others as shown in Table 1. Group 3 is due to diseases of lung parenchyma or hypoxia related. Group $4 \mathrm{PH}$ is due to chronic thromboembolic pulmonary hypertension (CTEPH) and other pulmonary obstructive processes. Group 5 includes diseases with multifactorial mechanisms 
or unclear mechanisms.

The $6^{\text {th }}$ WSPH proceedings stressed on the drugs and toxins associated PAH to help treating physicians to identify the culprit drug and perform specific surveillance during evaluation (Table 2). There is clear evidence to suggest that amphetamines/methamphetamines and dasatinib are definitely associated with development of PAH $(4,5)$. Dasatinib is a drug approved for treatment of leukemia and is a type of tyrosine kinase inhibitor. One of the series from France found PAH incidence of $0.45 \%$ (5). Dasatinib related $\mathrm{PAH}$ generally improves upon cessation of exposure of the drug but in roughly one third of patients it may persist $(5,6)$. In this update, long term responders to CCB were added as a separate subgroup of group1 PAH. Although remodeling of the small pulmonary vasculature is the commonest pathological finding in PAH, pulmonary vasoconstriction also plays an important role in $\mathrm{PAH}$ pathophysiology. This is a hallmark of patients with positive vasoreactivity. Acute

Table 2 Classification of drugs and toxins associated with PAH (adapted from the 6th WSPH)

\begin{tabular}{ll}
\hline Definite & Possible \\
\hline Aminorex & Cocaine \\
Fenfluramine & Phenylpropanolamine \\
Dexfenfluramine & L-tryptophan \\
Benfluorex & St John's wort \\
Methamphetamines & Amphetamines \\
Dasatinib & Interferon- $\alpha$ and - $\beta$ \\
Toxic rapeseed oil & Alkylating agents \\
& Bosutinib \\
& Direct-acting antiviral agents against \\
& hepatitis C virus leflunomide \\
& Indirubin (Chinese herb Qing-Dai) \\
\hline
\end{tabular}

$\mathrm{PAH}$, pulmonary arterial hypertension. vasodilator response was observed in $12.5 \%$ of a large series of $557 \mathrm{PAH}$ patients, $6.8 \%$ of these patients had a longterm clinical and hemodynamic response to CCBs (7). Acute vasodilator response is defined as a drop of more than $10 \mathrm{mmHg}$ in mPAP to go below $\mathrm{mPAP} \leq 40 \mathrm{mmHg}$ associated with an increased or unchanged CO. Many agents have been used for vasoreactivity testing with inhaled nitric oxide at $10-20 \mathrm{ppm}$ as the preferred agent but intravenous epoprostenol, adenosine or inhaled iloprost can be used as well $(7,8)$.

\section{Hemodynamic definition of PH}

Since 1973, PH has been defined as a mean pulmonary artery (mPAP) of $\geq 25 \mathrm{mmHg}$, however, the $6^{\text {th }} \mathrm{WSPH}$, task force recommended that this definition should be changed to mPAP $>20 \mathrm{mmHg}$ (2). The original definition of $\mathrm{mPAP}$ of $\geq 25 \mathrm{mmHg}$ was chosen somewhat arbitrarily and does not represent the upper limit of normal mPAP in the general population. All prior hemodynamic studies in healthy individuals have found that normal mPAP is approximately $14 \pm 3.3 \mathrm{mmHg}$ and the upper limit $\left(>97.5^{\text {th }}\right.$ percentile) of normal is $20 \mathrm{mmHg}$ (9). This new definition has scientific merit but appears to have less practical value. Major concerns regarding inclusion of individuals with mPAP between 21 and $24 \mathrm{mmHg}$ is the risk of $\mathrm{PH}$ diagnosis in these otherwise healthy individuals as very few people are symptomatic at this pressure. Baseline characteristics of REVEAL registry showed $\mathrm{mPAP}$ of $50 \mathrm{mmHg}$ at the time of diagnosis (10). This pressure range is way above than the currently accepted range of $25 \mathrm{mmHg}$. This highlights that patients become clinically symptomatic at a much higher pressure range. Thus, it will be difficult to identify patients at range of $21-24 \mathrm{mmHg}$. Additionally, there is data lacking at present about the treatment of this population. Although, few recent studies suggest that individuals with mPAP 21-24 tend to progress to "overt $\mathrm{PH}$ ( $\mathrm{mPAP} \geq 25 \mathrm{mmHg}$ )" more often than patients with $\mathrm{mPAP} \leq 20 \mathrm{mmHg}$ over a

Table 3 Updated hemodynamic definition based on the 6th WSPH, adapted from the original WSPH document (with prior permission)

\begin{tabular}{llc}
\hline Definition & Characteristics & Clinical groups (WHO group) \\
\hline Pre-capillary PH & mPAP $>20 \mathrm{mmHg}$, PAWP $\leq 15 \mathrm{mmHg}$, PVR $\geq 3$ WU & $1,3,4,5$ \\
Isolated post-capillary PH (IpcPH) & mPAP $>20 \mathrm{mmHg}$, PAWP $>15 \mathrm{mmHg}$, PVR $<3$ WU & 2 and 5 \\
Combined pre- and post-capillary PH (CpcPH) & mPAP $>20 \mathrm{mmHg}$, PAWP $>15 \mathrm{mmHg}$, PVR $\geq 3$ WU & 2 and 5 \\
\hline
\end{tabular}

Group 1: PAH; group 2: PH due to left heart disease; group 3: $\mathrm{PH}$ due to lung diseases and/or hypoxia; group 4: $\mathrm{PH}$ due to pulmonary artery obstructions; group 5: $\mathrm{PH}$ with unclear and/or multifactorial mechanisms. mPAP, mean pulmonary arterial pressure; PAWP, pulmonary arterial wedge pressure; PVR, pulmonary vascular resistance; WU, Wood units. 


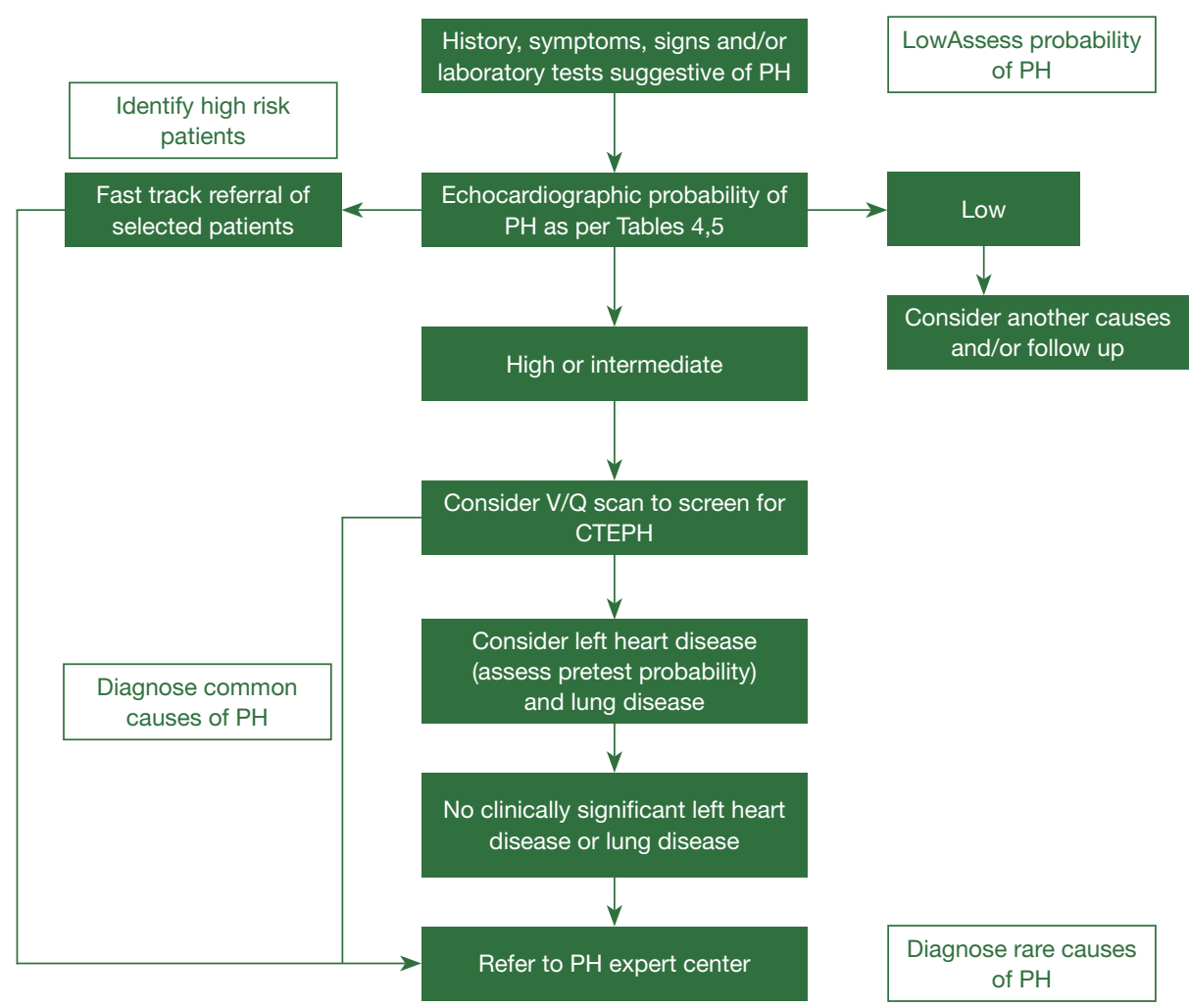

Figure 1 Algorithm highlighting PH evaluation at a community setting (Tables 4,5). PH, pulmonary hypertension.

$2-3$ year follow up $(11,12)$ and these individuals have a high morbidity and mortality over this same time period (13). Based on these data, the $6^{\text {th }} \mathrm{WSPH}$ task force recommended that a new mPAP $>20 \mathrm{mmHg}$ cut-off for diagnosing $\mathrm{PH}$ is both clinically warranted and in the best interest of the patient.

Another major hemodynamic change recommended by the $6^{\text {th }}$ WSPH update is the inclusion of pulmonary vascular resistance (PVR) in all forms of $\mathrm{PH}$. All $\mathrm{PH}$ ( $\mathrm{mPAP}>20 \mathrm{mmHg}$ ) will be further subclassified as pre-capillary $\mathrm{PH}(\mathrm{PAH})$, isolated post-capillary $\mathrm{PH}(\mathrm{IpcPH})$ or combined pre- and post-capillary $\mathrm{PH}(\mathrm{CpcPH})$ based on pulmonary arterial wedge pressure (PAWP) and PVR. While the threshold and application of significant PAWP has not changed $(\leq 15 \mathrm{mmHg}$ in $\mathrm{PAH},>15 \mathrm{mmHg}$ in all post capillary $\mathrm{PH})$, PVR now defines the presence or absence of pre-capillary $\mathrm{PH}(\mathrm{PVR}<3 \mathrm{WU}=\mathrm{IpcPH}, \mathrm{PVR} \geq 3 \mathrm{WU}$ in $\mathrm{PAH}$ and $\mathrm{CpcPH}$ ) (2) (Table 3). However, the method of detecting $\mathrm{CpcPH}$ remains controversial and that while $\mathrm{PVR} \geq 3 \mathrm{WU}$ has strong evidence to support its diagnostic utility, other hemodynamic markers such as the trans pulmonary gradient (TPG) and pulmonary arterial compliance (PAC) have demonstrated value in two meta-analyses for clarifying the diagnosis in at risk individuals $(14,15)$.

\section{Evaluation of PH}

Despite the advances in our understanding of symptomatology, progression and management, there has not been much progress in the early diagnosis of the disease in the last two decades. All guidelines and proceeding documents have a common message of early referral to a PAH expert center but this is yet an unsuccessful goal to achieve. Figure 1 gives an overview of the algorithm which should be used in evaluating patients with suspected PAH. REVEAL registry showed in roughly $21 \%$ of patients there was delay of over two years from the symptom onset and the correct diagnosis of PAH (16). A thorough history and examination may give clues for early diagnosis of the disease.

\section{Symptoms of $P H$}

There should be a high index of suspicion to diagnose PH. Appropriate screening tests should be performed in patients 
Table 4 Echocardiographic probability of pulmonary hypertension $(\mathrm{PH})$ in symptomatic patients with a suspicion of $\mathrm{PH}$, adapted from the original WSPH document (with prior permission)

\begin{tabular}{lcc}
\hline Peak tricuspid regurgitation velocity, $\mathrm{m} / \mathrm{s}$ & Presence of other echocardiographic "PH signs" & Echocardiographic probability of PH \\
\hline$\leq 2.8$ or not measurable & No & Low \\
$>2.8$ or not measurable, $2.9-3.4$ & Yes, no & Intermediate \\
$2.9-3.4,>3.4$ & Yes, not required & High \\
\hline
\end{tabular}

Table 5 Chocardiographic signs suggesting pulmonary hypertension (PH), adapted from the original WSPH document (with prior permission)

\begin{tabular}{lll}
\hline (A) The ventricles & (B) Pulmonary artery & (C) Inferior vena cava and right atrium \\
\hline $\begin{array}{l}\text { Right ventricle/left ventricle basal } \\
\text { diameter ratio }>1.0\end{array}$ & $\begin{array}{l}\text { Right ventricular outflow Doppler acceleration } \\
\text { time }<105 \mathrm{~ms} \text { and/or mid-systolic notching }\end{array}$ & $\begin{array}{l}\text { Inferior cava diameter }>21 \mathrm{~mm} \text { with decreased } \\
\text { inspiratory collapse }(<50 \% \text { with a sniff or }<20 \% \\
\text { with quiet inspiration) }\end{array}$ \\
$\begin{array}{l}\text { Flattening of the interventricular } \\
\begin{array}{l}\text { septum (left ventricular eccentricity } \\
\text { index }>1.1 \text { in systole and/or diastole) }\end{array}\end{array}$ & $\begin{array}{l}\text { Early diastolic pulmonary regurgitation velocity } \\
\text { m. }\end{array}$ & Right atrial area (end-systole) $>18 \mathrm{~cm} \mathrm{~s}^{-1}$
\end{tabular}

Pulmonary artery diameter $>25 \mathrm{~mm}$

Echocardiographic signs from at least two different categories $(A / B / C)$ from the list should be present to alter the level of echocardiographic probability of $\mathrm{PH}$.

with suspicion of $\mathrm{PH}$. Symptoms of $\mathrm{PH}$ are nonspecific. REVEAL registry data showed dyspnea on exertion to be the most common symptom of $\mathrm{PH}$, seen in over $85 \%$ of patients (16). Other common symptoms are chest discomfort, palpitations, leg edema and fatigue. Syncope/ presyncope is an important symptom in $\mathrm{PAH}$ and indicates severe form of the disease. In REVEAL registry syncope/ presyncope was seen in roughly $16 \%$ of patients diagnosed within two years of symptom onset and $18 \%$ of those diagnosed after two years of symptom onset (16). Presence of edema, ascites, abdominal distension indicates advanced stage or a rapidly progressing disease leading to rightsided heart failure. Rarely, hemoptysis or hoarseness due to unilateral vocal cord paralysis (Ortner's syndrome) by compression of the left recurrent laryngeal nerve can occur. Wheezing may be caused by large airway compression and angina due to myocardial ischemia caused by compression of the left main coronary artery by enlarged pulmonary artery (17). Dissection and rupture of PA can occur rarely if it is massively dilated or has aneurysmal dilatation and may present as cardiac tamponade.

\section{Physical examination findings}

The physical signs of $\mathrm{PH}$ include right ventricular heave, an accentuated pulmonary component of the second heart sound, an RV third heart sound, a pansystolic murmur of tricuspid regurgitation and a diastolic murmur of pulmonary regurgitation. Elevated jugular venous pressure, hepatomegaly, ascites, peripheral edema and cool extremities characterize right heart failure. Pulmonary exam is generally devoid of crackles or wheezing (18). In patients with scleroderma or other connective tissue disease, findings of telengectasia, digital ulceration and sclerodactyly may be seen. Presence of inspiratory crackles in these patients may point towards interstitial lung disease. Patients with liver disease may show spider naevi, testicular atrophy and palmer erythema. Digital clubbing is an important finding most frequently encountered in patients with PVOD, cyanotic congenital heart disease, interstitial lung disease or liver disease.

\section{Diagnostic testing}

\section{Electrocardiography (EKG)}

Suspected patients with $\mathrm{PH}$ must undergo a comprehensive evaluation. EKG can provide an early clue to the presence of $\mathrm{PH}$. An abnormal EKG may indicate more severe disease than mild $(19,20)$. EKG may show changes suggestive of right atrial or ventricular dilatation like, right bundle branch block (RBB), right axis deviation (RAD), $\mathrm{P}$ pulmonale, RV hypertrophy, RV strain, and QTc prolongation. RV strain is 
more sensitive finding in comparison to RV hypertrophy.

\section{Hematological testing}

Hematological testing does not give a direct diagnostic clue but it is an important testing to explain end-organ compromise. It is also helpful for finding the etiology of $\mathrm{PH}$ especially in patients with suspected auto-immue process or connective tissue disease. Routine testing with thyroid function, biochemistry and hematology is essential for evaluation. Evaluation for liver function is essential as liver function abnormalities may be present due to hepatic congestion due to right heart failure, primary liver disease (in cases of porto-PH) or as a result of liver injury due to use of endothelin receptor antagonist. Thyroid disease is common in PAH and may mimic clinical picture of right heart failure. Elevated brain natriuretic peptide (BNP) and N-terminal pro-BNP (NT-proBNP) indicates poor response to treatment or worsening disease. Persistently elevated BNP or NT-proBNP are indicators of worse outcome. All patients must be checked for HIV, hepatitis and CTD. ANA testing should be done routinely and ANA immunofluorescence testing is recommended against ELISA technique and anything more than 1:160 titer should be considered as positive. If there is high index of suspicion, disease specific CTD testing should be done, for example, if scleroderma is suspected, patients should be checked for anticentromere, antitopoisomerase, anti-RNA polymerase III. Hypercoagulable testing like thrombophilia panel including anticardiolipin antibodies, lupus anticoagulant and anti- $\beta 2$-glycoprotein antibodies should be done in patients with CTEPH.

\section{Pulmonary function tests}

A decrease in the diffusion capacity of the lung for carbon monoxide (DLCO) is the earliest change seen in pulmonary function tests in patients with pulmonary vascular diseases. All patients with PAH must undergo routine spirometry measurements with forced expiratory volume, forced vital capacity in addition to total lung capacity measurement. Most patients with PAH may show a mild restrictive defect. In very early disease, diffusion capacity can be normal in PAH. An abnormally lower DLCO, defined as $<45 \%$ of predicted, is associated with a poor outcome $(21,22)$. Suspect PVOD, scleroderma or concomitant ILD in the setting of marked reduction of DLCO. Patients with $\mathrm{PH}$ in the setting of combined pulmonary fibrosis and emphysema (CPFE), marked reduction in DLCO can be seen in association with relatively preserved lung volumes. ILD patients may show reduction of forced vital capacity (FVC) or total lung capacity (TLC) (23). Overnight oximetry or sleep study must be done in patients with suspected sleep disordered breathing. Cardiopulmonary exercise testing (CPET) can also help in evaluating patients with exercise limitation. It can help in pointing towards the etiology of dyspnea on exertion.

\section{Echocardiography}

Echocardiography is an excellent screening tool for PH. If echocardiography suggests evidence of $\mathrm{PH}$, it must be confirmed with right heart catheterization (RHC) (18). The pulmonary artery systolic pressure (PASP) is calculated based on the tricuspid regurgitation velocity (TRV). It is calculated based on the simplified Bernoulli equation taking into account right atrial pressure (RAP). Respiratory variation in diameter of the inferior vena cava (IVC) helps in estimating the RAP. An IVC diameter $<21 \mathrm{~mm}$ with $>50 \%$ collapsibility with respiration suggests a normal RAP i.e., between 0-5 $\mathrm{mmHg}$, whereas an IVC diameter $>21 \mathrm{~mm}$ with $<50 \%$ collapsibility indicates a higher RAP between $10-20 \mathrm{mmHg}$. In scenarios in which the IVC diameter and collapse do not fit this model, an intermediate value of 8 $\mathrm{mmHg}$ may be used $(18,24,25)$. Considering the inaccuracies in calculating RAP, the $6^{\text {th }} \mathrm{WSPH}$ recommends (17) using tricuspid regurgitant jet velocity (TRV) to assess the presence/absence or grade the severity of PH (Table 4) in the presence or absence of other pre-specified echocardiographic variables to suggest $\mathrm{PH}$. Table 5 summarizes several additional criteria to indicate probability of $\mathrm{PH}$ based on the RV, PA, RA and IVC imaging findings. A contrast echocardiography must be done if obtained images are of poor quality and peak TRV is difficult to estimate. Severe TRV leads to underestimation of tricuspid regurgitant jet and cannot exclude $\mathrm{PH}$.

\section{Ventilation-perfusion scan of the lungs}

All patients undergoing evaluation for $\mathrm{PH}$ must undergo a ventilation/perfusion (V/Q) lung scan testing to rule out CTEPH. It is essential to correctly diagnose CTEPH as this is one of those forms of $\mathrm{PH}$ where a potentially curative surgical treatment option is available. Multiple studies have confirmed the superiority of the V/Q scan as being more sensitive and specific to diagnose CTEPH in comparison to CT pulmonary angiogram (CTPA) (26). A V/Q scan has a sensitivity of $90-100 \%$ and a specificity of $94-100 \%$ to diagnose CTEPH (26). Newer techniques such as threedimensional magnetic resonance (MR) perfusion mapping 


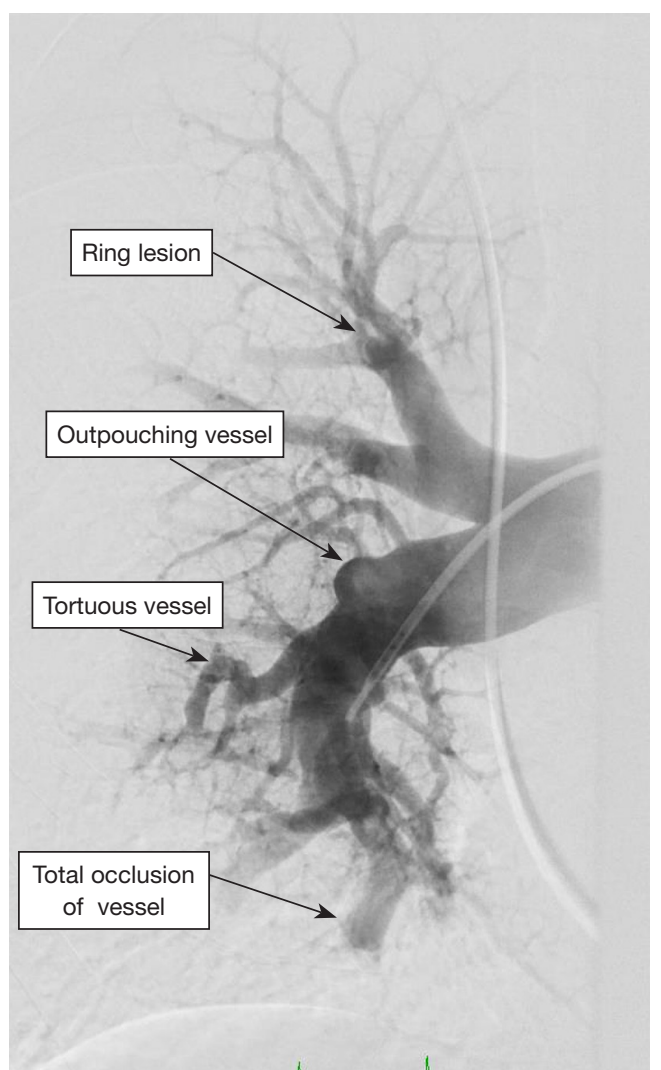

Figure 2 Pulmonary angiogram of a patient with CTEPH showing classical lesions seen in CTEPH. CTEPH, chronic thromboembolic pulmonary hypertension.

have been shown to be as sensitive as traditional perfusion scintigraphy in screening for CTEPH. MR is a radiationfree modality to assess both ventilation and perfusion in CTEPH (27).

\section{Computed tomography: high resolution, contrast-enhanced and pulmonary angiography}

Computed tomography (CT) of the chest is an important investigation in the evaluation of PH. It is widely available, easily done and reproducible. It provides important information about lung parenchyma, vascular, cardiac and mediastinal abnormalities. Enlargement of PA or RV or RA on CT imaging may suggest $\mathrm{PH}$. Concomitant presence of lung parenchymal disease may indicate $\mathrm{PH}$ due to lung disease. Experienced centers may use a CT angiography for evaluation of CTEPH as well. Presence of esophageal dilation on CT may suggest SSc, congenital cardiac defects such as anomalous pulmonary venous drainage can be detected on contrast CTA and may provide prognostic information (28).

Incidentally detected enlarged PA diameter of more than $\geq 29 \mathrm{~mm}$ or an increased ratio of PA diameter to aortic diameter of more than 1.0 may indicate presence of PH. Presence of increased ratio of segmental artery to bronchus $>1: 1$ in three or four lobes is associated with a high specificity for PH (29,30). High-resolution CT is standard of care to diagnose ILD and emphysema. It may additionally provide information regarding PVOD with the presence of interstitial edema with diffuse central ground-glass opacity and thickened interlobular septa with lymphadenopathy (31). CT angiography of the PA is a very helpful tool in evaluation of PH when CTEPH is suspected. It can help in identifying the lesions which are surgically resect-able with pulmonary endarterectomy (PEA) or benefit from BPA $(32,33)$. Commonly identified lesions are webs, complete obstruction, bands and intimal irregularities (Figure 2). At an experienced center, a CTA can identify these lesions as accurately and reliably as digital subtraction angiography $(34,35)$. Conventional pulmonary angiography is still the standard of care and is mandatory in the evaluation of CTEPH to identify the surgical candidates.

\section{Right heart catheterization}

RHC is an essential testing needed to confirm the diagnosis of $\mathrm{PH}$. In an experienced center, RHC has low morbidity $(1.1 \%)$ and mortality of (0.055\%) (36). RHC should be done at an experienced center as it requires meticulous attention to details in obtaining the correct hemodynamic information with minimal risk for complications. During a RHC, all pressure measurements are done in end expiration during normal tidal respiration, without breath holding. Pressure measurements should be done in the pulmonary artery (PA), PA wedge position, right ventricle (RV) and right atrium (RA). Oxygen saturation should be done at the minimum from superior vena cava (SVC), RA and PA. If PA saturation is more than $75 \%$ then oxygen saturation should be done in each cardiac chamber to evaluate for left to right shunting (18). Thermodilution or the direct Fick methods are used to measure cardiac output. Thermodilution cardiac output is measured in set of three measurements and is considered reliable even in low flow states or severe TR (37). Thermodilution cardiac output may be less reliable in patients with intracardiac shunting due to early recirculation of the injectate volume. Direct Fick method is preferred method but it is not widely available, indirect Fick is acceptable but not a reliable method. Hemodynamic definition and vasoreactivity 
testing is discussed earlier in this review. Other derived parameters which must be obtained in a RHC for $\mathrm{PH}$ evaluation are PVR, transpulmonary pressure and diastolic pressure gradient (DPG). A PVR $>3 \mathrm{WU}$ is essential to establish the diagnosis of PAH (2). The DPG is defined as difference between the mean PAWP and diastolic PAP and is not much affected by the filling pressures or flow variations (38) but may not have prognostic value (39). Studies have shown validity of DPG in patients with suspected PH due to left heart disease (40).

\section{Genetic testing}

BMPR2 mutations remain the most common genetic cause of PAH, accounting for $\sim 80 \%$ of hereditary (HPAH) and $\sim 20 \%$ idiopathic PAH (IPAH) (41). Besides BMPR2, other TGF- $\beta$ superfamily genes including ALK1/ACVRL1 (a heterodimeric partner of BMPR2), BMP9 (a BMPR2 ligand), ENG (a coreceptor for BMPR2 signaling), and SMAD1, 4, and 9 (downstream BMP signaling molecules) and have been linked to both HPAH and IPAH (42). In the last five years whole exome sequencing (WES) in BMPR2 negative HPAH patients led to the discovery of two other genes: CAV1 (involved in BMPR2 membrane localization and signaling) (43) and KCNK3 (a potassium channel that regulates resting membrane potential) (44). In pediatric population, WES recently identified TBX4, a gene linked to small patella syndrome (45) in patients with HPAH.

EIF2AK4 (a kinase involved in amino acid metabolism) is associated with both PVOD and PCH $(46,47)$. In contrast to BMPR2, EIF2AK4 mutations are autosomal recessive and completely penetrant. Presence of EIF2AK4 in a PAH patient can establish the diagnosis of $\mathrm{PVOD} / \mathrm{PCH}$ in without necessitating lung biopsy (47).

Genetic evaluation of PAH should be done under the guidance of a genetic counselor. Inheritance of these mutations is complex and it adds nuance to the difficult task of genetic counseling to patients with a family or personal history of HPAH looking to conceive. This comes with immense psychological concerns of genetic screening for a disease with no prevention or cure. The genetic screening offers potential benefit with early detection of family members and earlier initiation of therapy when indicated. The $6^{\text {th }}$ WSPH Task Force recommended that genetic screening should be done under the guidance of a genetic counselor or clinical geneticist (48). At this point, a pedigree can be generated to identify relatives at risk, though gene testing or screening should be initiated with affected patients. It should be done be done at experienced centers by the trained and experienced geneticists.

\section{Advanced imaging techniques}

Recently many advances have been made in imaging techniques with the goal of early and accurate detection of the disease. VQ single photon emission CT (SPECT) (49-51), dual energy CT (52), three dimensional dynamic contrast enhanced magnetic resonance for assessment of lung perfusion (27,53), functional magnetic resonance imaging for ventilation (54), cardiac magnetic resonance imaging for RV function and strain have been suggested to aid in the diagnosis or prognosis in $\mathrm{PH}$ and CTEPH in smaller studies (55-58) but their role in routine clinical practice is yet to be defined.

\section{Conclusions}

$\mathrm{PH}$ is a complex disease with suboptimal survival. Its diagnosis, assessment and management warrants a comprehensive, detail oriented approach at an expert center. Almost all guidelines, consensus statements and proceeding documents have strongly recommended early referral to an expert center to have a meaningful improvement in the outcome of the patients living with this disease.

\section{Acknowledgments}

None.

\section{Footnote}

Conflicts of Interest: The author serves on the speaker panel for Actelion pharmaceuticals, Bayer and United therapeutics; has received honoraria from these entities for consultancy and speaking engagements. Member of a data safety and monitoring board for an industry sponsored FDA approved study. The author is PI or Sub I on multiple clinical trials sponsored by Actelion and United therapeutics.

Ethical Statement: The author is accountable for all aspects of the work in ensuring that questions related to the accuracy or integrity of any part of the work are appropriately investigated and resolved.

\section{References}

1. Galiè N, McLaughlin VV, Rubin LJ, et al. An overview of the 6th World Symposium on Pulmonary Hypertension. 
Eur Respir J 2019;53:1802148.

2. Simonneau G, Montani D, Celermajer DS, et al. Haemodynamic definitions and updated clinical classification of pulmonary hypertension. Eur Respir J 2019;53:1801913.

3. Benza RL, Miller DP, Barst RJ, et al. An evaluation of long-term survival from time of diagnosis in pulmonary arterial hypertension from the REVEAL registry. Chest 2012;142:448-56.

4. Zamanian RT, Hedlin H, Greuenwald P, et al. Features and outcomes of methamphetamine-associated pulmonary arterial hypertension. Am J Respir Crit Care Med 2018;197:788-800.

5. Montani D, Bergot E, Günther S, et al. Pulmonary arterial hypertension in patients treated by dasatinib. Circulation 2012;125:2128-37.

6. Weatherald J, Chaumais MC, Savale L, et al. Longterm outcomes of dasatinib-induced pulmonary arterial hypertension: a population-based study. Eur Respir J 2017;50:1700217.

7. Sitbon $\mathrm{O}$, Humbert M, Jaïs $\mathrm{X}$, et al. Long-term response to calcium channel blockers in idiopathic pulmonary arterial hypertension. Circulation 2005;111:3105-11.

8. Rich S, Kaufmann E, Levy PS. The effect of high doses of calcium-channel blockers on survival in primary pulmonary hypertension. N Engl J Med 1992;327:76-81.

9. Kovacs G, Berghold A, Scheidl S, Pulmonary arterial pressure during rest and exercise in healthy subjects: a systematic review. Eur Respir J 2009;34:888-94.

10. Badesch DB, Raskob GE, Elliott CG, et al. Pulmonary arterial hypertension: baseline characteristics from the REVEAL Registry. Chest 2010;137:376-87.

11. Valerio CJ, Schreiber BE, Handler CE, Borderline mean pulmonary artery pressure in patients with systemic sclerosis: transpulmonary gradient predicts risk of developing pulmonary hypertension. Arthritis Rheum 2013;65:1074-84.

12. Coghlan JG, Wolf M, Distler O, Incidence of pulmonary hypertension and determining factors in patients with systemic sclerosis. Eur Respir J 2018;51. doi: 10.1183/13993003.01197-2017.

13. Douschan P, Kovacs G, Avian A, Mild Elevation of Pulmonary Arterial Pressure as a Predictor of Mortality. Am J Respir Crit Care Med 2018;197:509-16.

14. Vanderpool RR, Saul M, Nouraie M, Association Between Hemodynamic Markers of Pulmonary Hypertension and Outcomes in Heart Failure With Preserved Ejection Fraction. JAMA Cardiol 2018;3:298-306.
15. Caravita S, Dewachter C, Soranna D, Haemodynamics to predict outcome in pulmonary hypertension due to left heart disease: a meta-analysis. Eur Respir J 2018;51. doi: 10.1183/13993003.02427-2017.

16. Brown LM, Chen H, Halpern S, et al. Delay in recognition of pulmonary arterial hypertension: factors identified from the REVEAL Registry. Chest 2011;140:19-26.

17. Frost A, Badesch D, Gibbs JSR, et al. Diagnosis of pulmonary hypertension. Eur Respir J 2019;53:1801904.

18. Galiè N, Humbert M, Vachiery JL, et al. 2015 ESC/ERS Guidelines for the diagnosis and treatment of pulmonary hypertension. Eur Respir J 2015;46:903-75.

19. Bossone E, Paciocco G, Iarussi D, et al. The prognostic role of the ECG in primary pulmonary hypertension. Chest 2002;121:513-8.

20. Henkens IR, Gan CT, van Wolferen SA, et al. ECG monitoring of treatment response in pulmonary arterial hypertension patients. Chest 2008;134:1250-7.

21. Trip P, Nossent EJ, de Man FS, et al. Severely reduced diffusion capacity in idiopathic pulmonary arterial hypertension: patient characteristics and treatment responses. Eur Respir J 2013;42:1575-85.

22. Sun XG, Hansen JE, Oudiz RJ, et al. Pulmonary function in primary pulmonary hypertension. J Am Coll Cardiol 2003;41:1028-35.

23. Nathan SD, Barbera JA, Gaine SP, et al. Pulmonary hypertension in chronic lung disease and hypoxia. Eur Respir J 2019;53:1801914.

24. Rudski LG, Lai WW, Afilalo J, et al. Guidelines for the echocardiographic assessment of the right heart in adults: a report from the American Society of Echocardiography endorsed by the European Association of Echocardiography, a registered branch of the European Society of Cardiology, and the Canadian Society of Echocardiography. J Am Soc Echocardiogr 2010;23:685-713.

25. Lang RM, Badano LP, Mor-Avi V, et al. Recommendations for cardiac chamber quantification by echocardiography in adults: an update from the American Society of Echocardiography and the European Association of Cardiovascular Imaging. Eur Heart J Cardiovasc Imaging 2015;16:233-70.

26. Tunariu N, Gibbs SJR, Win Z, et al. Ventilation-perfusion scintigraphy Is more sensitive than multidetector CTPA in detecting chronic thromboembolic pulmonary disease as a treatable cause of pulmonary hypertension. J Nucl Med 2007;48:680-4.

27. Rajaram S, Swift AJ, Telfer A, et al. 3D contrast-enhanced 
lung perfusion MRI is an effective screening tool for chronic thromboembolic pulmonary hypertension: results from the ASPIRE Registry. Thorax 2013;68:677-8.

28. Rajaram S, Swift AJ, Condliffe R, et al. CT features of pulmonary arterial hypertension and its major subtypes: a systematic CT evaluation of 292 patients from the ASPIRE Registry. Thorax 2015;70:382-7.

29. Shen Y, Wan C, Tian P, et al. CT-base pulmonary artery measurement in the detection of pulmonary hypertension: a meta-analysis and systematic review. Medicine (Baltimore) 2014;93:e256.

30. Tan RT, Kuzo R, Goodman LR, et al. Utility of CT scan evaluation for predicting pulmonary hypertension in patients with parenchymal lung disease. Chest 1998;113:1250-6.

31. Resten A, Maitre S, Humbert M, et al. Pulmonary hypertension: CT of the chest in pulmonary venoocclusive disease. AJR Am J Roentgenol 2004;183:65-70.

32. Fedullo PF, Auger WR, Kerr KM, et al. Chronic thromboembolic pulmonary hypertension. N Engl J Med 2001;345:1465-72.

33. Fukui S, Ogo T, Morita Y, et al. Right ventricular reverse remodelling after balloon pulmonary angioplasty. Eur Respir J 2014;43:1394-402.

34. Dartevelle P, Fadel E, Mussot S, et al. Chronic thromboembolic pulmonary hypertension. Eur Respir J 2004;23:637-48.

35. Reichelt A, Hoeper MM, Galanski M, et al. Chronic thromboembolic pulmonary hypertension: evaluation with 64-detector row CT versus digital substraction angiography. Eur J Radiol 2009;71:49-54.

36. Hoeper MM, Lee SH, Voswinckel R, et al. Complications of right heart catheterization procedures in patients with pulmonary hypertension in experienced centers. J Am Coll Cardiol 2006;48:2546-52.

37. Hoeper MM, Maier R, Tongers J, et al. Determination of cardiac output by the Fick method, thermodilution, and acetylene rebreathing in pulmonary hypertension. Am J Respir Crit Care Med 1999;160:535-41.

38. Naeije R, Vachiery JL, Yerly P, et al. The transpulmonary pressure gradient for the diagnosis of pulmonary vascular disease. Eur Respir J 2013;41:217-23.

39. Tedford RJ, Beaty CA, Mathai SC, et al. Prognostic value of the pre-transplant diastolic pulmonary artery pressureto-pulmonary capillary wedge pressure gradient in cardiac transplant recipients with pulmonary hypertension. J Heart Lung Transplant 2014;33:289-97.

40. Vachiéry JL, Adir Y, Barbera JA, et al. Pulmonary hypertension due to left heart disease. J Am Coll Cardiol 2013;62:D100-8.

41. Tielemans B, Delcroix M, Belge C, TGFbeta and BMPRII signalling pathways in the pathogenesis of pulmonary arterial hypertension. Drug Discov Today 2019;24:703-16.

42. Austin ED, Loyd JE. The genetics of pulmonary arterial hypertension. Circ Res 2014;115:189-202.

43. Austin ED, Ma L, LeDuc C, et al. Whole exome sequencing to identify a novel gene (caveolin-1) associated with human pulmonary arterial hypertension. Circ Cardiovasc Genet 2012;5:336-43.

44. Ma L, Roman-Campos D, Austin ED, et al. A novel channelopathy in pulmonary arterial hypertension. N Engl J Med 2013;369:351-61.

45. Zhu N, Gonzaga-Jauregui C, Welch CL, et al. Exome Sequencing in Children With Pulmonary Arterial Hypertension Demonstrates Differences Compared With Adults. Circ Genom Precis Med 2018;11:e001887.

46. Best DH, Sumner KL, Smith BP, et al. EIF2AK4 Mutations in Patients Diagnosed With Pulmonary Arterial Hypertension. Chest 2017;151:821-8.

47. Eyries M, Montani D, Girerd B, et al. EIF2AK4 mutations cause pulmonary veno-occlusive disease, a recessive form of pulmonary hypertension. Nat Genet 2014;46:65-9.

48. Morrell NW, Aldred MA, Chung WK, et al. Genetics and genomics of pulmonary arterial hypertension. Eur Respir J 2019;53. doi: 10.1183/13993003.01899-2018.

49. Leblanc M, Leveillée F, Turcotte E. Prospective evaluation of the negative predictive value of V/Q SPECT using 99mTc-Technegas. Nucl Med Commun 2007;28:667-72.

50. Grüning T, Drake BE, Farrell SL, et al. Three-year clinical experience with VQ SPECT for diagnosing pulmonary embolism: diagnostic performance. Clin Imaging 2014;38:831-5.

51. Gutte H, Mortensen J, Jensen CV, et al. Detection of pulmonary embolism with combined ventilationperfusion SPECT and low-dose CT: head-to-head comparison with multidetector CT angiography. J Nucl Med 2009;50:1987-92.

52. Giordano J, Khung S, Duhamel A, et al. Lung perfusion characteristics in pulmonary arterial hypertension (PAH) and peripheral forms of chronic thromboembolic pulmonary hypertension (pCTEPH): dual-energy CT experience in 31 patients. Eur Radiol 2017;27:1631-9.

53. Johns CS, Swift AJ, Rajaram S, et al. Lung perfusion: MRI vs. SPECT for screening in suspected chronic thromboembolic pulmonary hypertension. J Magn Reson Imaging 2017;46:1693-7. 
54. Nakagawa T, Sakuma H, Murashima S, et al. Pulmonary ventilation-perfusion MR imaging in clinical patients. J Magn Reson Imaging 2001;14:419-24.

55. Freed BH, Gomberg-Maitland M, Chandra S, et al. Late gadolinium enhancement cardiovascular magnetic resonance predicts clinical worsening in patients with pulmonary hypertension. J Cardiovasc Magn Reson 2012;14:11.

56. El Abouelnour A, Doyle M, Thompson DV, et al. Does late gadolinium enhancement still have value? Right ventricular internal mechanical work, Ea/Emax and late gadolinium enhancement as prognostic markers in patients with advanced pulmonary hypertension via cardiac MRI.

Cite this article as: Sahay S. Evaluation and classification of pulmonary arterial hypertension. J Thorac Dis 2019;11(Suppl 14):S1789-S1799. doi: 10.21037/jtd.2019.08.54
Cardiol Res Cardiovasc Med 2017;2017:CRCM-111.

57. Mehta BB, Auger DA, Gonzalez JA, et al. Detection of elevated right ventricular extracellular volume in pulmonary hypertension using Accelerated and NavigatorGated Look-Locker Imaging for Cardiac T1 Estimation (ANGIE) cardiovascular magnetic resonance. J Cardiovasc Magn Reson 2015;17:110.

58. de Siqueira ME, Pozo E, Fernandes VR, et al. Characterization and clinical significance of right ventricular mechanics in pulmonary hypertension evaluated with cardiovascular magnetic resonance feature tracking. J Cardiovasc Magn Reson 2016;18:39. 